\title{
Mediation in verbal paired-associate learning: the role of temporal factors
}

\author{
Rudolph W. Sehulz and Eugene A. Lovelace \\ STATE UNIVERSITY OF IOWA
}

\begin{abstract}
The results of two experiments with a paired associates three-stage mediation paradigm in which the strength of one segment of the mediation chain, length of test-list study and anticipation intervals were varied indicated that the length of the anticipation interval may be a crucial factor in determining whether mediation occurs.
\end{abstract}

\section{Introduetion}

The importance of mediation, and its central role in most theorizing about verbal processes, is clearly apparent from the steadily increasing number of research reports which have been concerned with this phenomenon. Moreover, there can now be little doubt that mediation is a demonstrable phenomenon (e. g., Russell \& Storms, 1955; Horton \& Kjeldergaard, 1961; McGehee \& Schulz, 1962). Therefore, as Jenkins has recently pointed out, the next step is, ". . . to press on in our experimental attack on the conditions of mediation; that is, we should attempt to discover how these implicit processes are acquired, how they are activated, how they are inhibited, and in general, how they are employed by the subject (1963, p. 212)." This next step was the concern of the present research.

\section{Experiment I}

All Ss learned three eight-item paired-associate (PA) lists in succession by the anticipation method on a memory drum. These lists consisted of paralog-noun, adjective-trigram, and paralog-trigram pairs, respectively. The paralogs were of low meaningfulness, according to Taylor (1959), and the trigrams, from Noble (1961), were of about $75 \%$ association value. Representing the three lists by $A-B, C-D, A-D$, the nouns and adjectives were chosen such that the strength of the association between B and C resulting from S's language habits, as inferred from the Underwood and Richardson (1956) norms, was varied over three levels as follows: (1) High--the mean percentages of Ss having given $\mathrm{Cs}$ as responses to $\mathrm{Bs}$ was $80 \%$. (2) Low--the mean percentages of Ss having given Cs as responses to $\mathrm{Bs}$ was $28 \%$. (3) Control--no association between B and $\mathrm{C}$ was evident from the norms. Thus, the effect of the strength of the $\mathrm{B}-\mathrm{C}$ associations on the mediation of test-list A-D pairs was one of the factors investigated in the present study.

The length of the test-list study interval ( $2 \mathrm{vs} .4 \mathrm{sec}$ ) was also manipulated. Our reasoning was that a long study interval would afford Ss more opportunity to discover the relationships which existed between $\mathrm{A}$ and $\mathrm{D}$ pairs than would a short interval. Moreover, this added time was expected to be particularly beneficial when the B-C association was weak. Accordingly, the testlist was presented at a $2: 2-\mathrm{sec}$. rate for half the Ss and at a $2: 4-\mathrm{sec}$. rate for the other half of the Ss.

Twenty Ss, undergraduates at the University of Iowa, were assigned randomly to each of the six respective conditions defined by the three levels of B-C strength at each of the two study intervals. The Ss were naive with respect to the particular materials used. All Ss learned the first two lists at a $2: 2-\mathrm{sec}$. rate to the criterion of a second trial on which all eight responses were anticipated correctly. The test list was presented for 15 anticipation trials after which the Ss were queried as to how they had learned this list.

\section{Results}

Test-list performance, in terms of the means and SDs for total number of correct responses during the 15 trials, is shown in Table 1. From Table 1 it can be seen that the differences among conditions, while in the expected direction, were disappointingly small and, with the exception of length of study interval as a main effect $(\mathrm{F}=15.49$, df $1 / 114, \mathrm{p}<.01)$, fail to attain acceptable standards of statistical reliability. Thus, it must be concluded that there is no clear evidence that either the strength of the B-C association or opportunity for the discovery of mediating associations affected test-list performance in the present study. Yet, theoretically, and on the basis of similar prior studies (e. g., Russell \& Storms, 1955; McGehee \& Schulz, 1962), there was every reason to expect mediated facilitation of test-list performance, at least with high-strength B-C associations. Why did the expected facilitation fail to occur? The second experiment reported here provides a tentative answer to this question.

The Ss' reports regarding test-list learning provided an important clue as to the nature of the answer to this question. Namely, several Ss commented that, although they were aware of the relationships between the mem-

Table 1. Mean Total Numbers of Correct Responses During 15 Trials of Test-list Performance.

Strength of

Language

$$
\text { High }
$$

Low

Control

Association

$2 \mathrm{sec}$

$\overline{\mathrm{X}}=63.8 \quad \overline{\mathrm{X}}=62.0$

$\overline{\mathrm{X}}=56.1$

Study

Interval

$\mathrm{SD}=19.82$

$\mathrm{SD}=25.20$

$\mathrm{SD}=19.20$

4 sec.
$\overline{\mathrm{X}}=74.7$

$\overline{\mathrm{X}}=70.5$

$\mathrm{SD}=18.28$

$\mathrm{SD}=17.99$
$\mathrm{SD}=22.03$ 


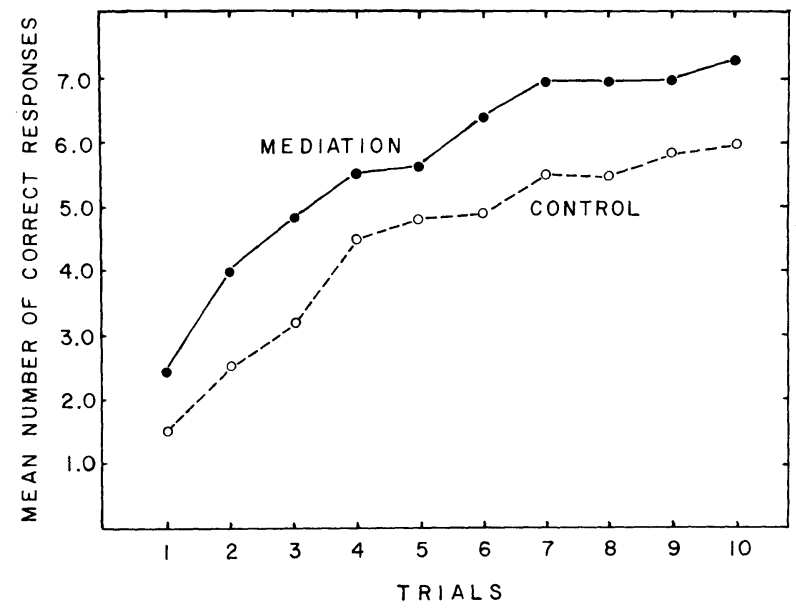

Fig. 1. Test-list performance under mediated and control conditions in Experiment 2 with a 4:2-sec. rate of presentation.

bers of the pairs on the test list, they were not able to utilize them because it took too long to complete the $\mathrm{A}-\mathrm{B}-\mathrm{C}-\mathrm{D}$ response chain during the 2-sec. anticipation interval.

\section{Experiment 2}

Evidently, it may be one thing to discover the existence of mediating associations, but quite another matter to utilize them effectively. This suggests, of course, that an increase in the length of the test-list anticipation interval under the mediated conditions of Experiment 1 would enhance the possibility for effective utilization of mediators and thereby facilitate performance under these conditions. Accordingly, in Experiment 2 a 4-sec. instead of a 2-sec. test-list anticipation interval was employed in replicating those two conditions of Experiment 1 where the B-C language associations had been strong (mediation) or absent (control) with a $2-\mathrm{sec}$. study interval. In all other respects the conditions of the present experiment were identical to those prevailing in Experiment 1 except that only 10 trials were given on the test list. Twenty Ss were assigned randomly to each of the two respective conditions in the present study.

The results of Experiment 2 are shown in Fig. 1. There it can be seen that test-list performance under the conditions where mediation was possible was clearly superior to performance under control conditions. Statistically, in terms of the mean total numbers of correct responses during the 10 test-list trials, the difference between these conditions is a reliable one $(t=2.25$, df $38, p<.05)$. Moreover, this result has received two independent replications as part of a study currently in progress.

\section{Discussion}

The present findings would appear to have a number of important implications for the theoretical and em- pirical analysis of mediational phenomena. For example, it would seem theoretically fruitful to postuate that discovery and utilization of mediating associations are differentiable aspects of the mediation process. That is, while the former aspect is obviously necessary, it is not sufficient. In this connection, it should be noted that Ss in Experiment 1 had in one case equal (2-sec. study interval) and in another case more (4-sec. study interval) opportunity to discover mediating associations than Ss in Experiment 2(2-sec. study interval); however, these associations could only be utilized in the latter study. Moreover, it may be expected that certain variables will have their primary influence on the discovery process while others affect mainly utilization.

In terms of the present data, it seems probable that the frequent previous failures (e. g., Jenkins, 1963) to obtain mediation effects and the generally small, albeit statistically significant, magnitude of these effects when they are observed (e. g., Horton \& Kjeldergaard, 1961) may, at least in part, have resulted from the use of test-list anticipation intervals that were too short for $\mathrm{S}$ to utilize the mediating associations he may have discovered. In the future, investigators may wish to take account of this possibility by insuring that the length of their test-list anticipation interval is compatible with the latency of S's covert mediating response, perhaps inferring these latencies from S's overt performance during the initial stages of a two or three stage mediation paradigm, and thereby insuring the desired compatibility.

\section{References}

HORTON, D. L., \& KJELDERGAARD, P. M. An experimental analysis of associative factors in mediated generalizations. Psychol. Monogr., 1961, 75, (11, Whole No. 515).

JENKINS, J J. Mediated associations: Paradigms and situations. In C. N. Cofer \& B. S. Musgrave (Eds.), Verbal behavior and learning. New York: McGrawHill, 1963. Pp. 210-245.

MCGEHEE, N. E., \& SCHULZ, R. W. Mediation in paired-associate learning. J.exp. Psychol., 1961, 62, 565-570.

NOBLE, C. E. Measurement of association value (a), rated associations (a'), and scaled meaningfulness (m') for the 2100 CVC combinations of the English alphabet. Psychol. Rep., 1961, 8, 487-521.

RUSSELL, W. A., \& STORMS, L. H. Implicit verbal chaining in paired-associate learning. J. exp. Psychol., 1955, 49, 287-293.

TAYLOR, J. D. The meaningfulness of 320 words and paralogs. Unpublished doctoral dissertation: Duke University, 1959.

UNDERWOOD, B. J., \& RICHARDSON, J. Some verbal materials for the study of concept formation. Psychol. Bull., 1956, 53, 84-95. 